\title{
Expression of Bax, Bcl-2, and P53 in Progressive Multifocal Leukoencephalopathy
}

\author{
Bin Yang, M.D., Ph.D, Richard A. Prayson, M.D. \\ Department of Anatomic Pathology, The Cleveland Clinic Foundation, Cleveland, Ohio
}

\begin{abstract}
It has been shown in vitro that JC viral protein can form a complex with wild-type p53 protein, which is a key regulator of both cell proliferation and cell death. Cellular factors, Bax and Bcl-2, are two essential downstream elements involved in p53dependent apoptosis. To determine whether association of JC virus with p53 protein affects the expression of Bax and Bcl-2 in viral-infected cells in progressive multifocal leukoencephalopathy (PML), we studied the expression of Bax, Bcl-2, and p53 in 14 cases from 13 PML patients by using paraffin immunohistochemistry. Seven of 13 patients were known to be HIV positive. Overexpression of p53 was found in viral-infected oligodendrocytes and some astrocytes in all 14 cases. Intense immunostaining of Bax was strongly expressed in viralinfected oligodendrocytes and astrocytes. Bax immunostaining was also found in macrophages in the demyelinating lesions. Bcl-2 was not detected in viral-infected glial cells. The expression pattern of Bax positive/Bcl-2 negative in viral-infected glial cells suggests that the oligodendrocyte may be undergoing apoptosis which may in turn contribute to the demyelinating process in PML. The coexpression of p53 and Bax in the infected glial cells suggests that p53 detected by immunohistochemistry may still maintain its wild-type function.
\end{abstract}

KEY WORDS: Apoptosis, Bax, Bcl-2, JC virus, p53, Progressive multifocal leukoencephalopathy.

Mod Pathol 2000;13(10):1115-1120

Progressive multifocal leukoencephalopathy (PML) is a demyelinating disease of the central nervous system that results from infection of oligodendrocytes with predominantly JC virus (JCV), a papovavirus (1). PML occurs predominantly in immunocompromised individuals. The incidence of PML has increased in the past decade, mainly due to increased numbers of AIDS patients (2). His-

Copyright $\odot 2000$ by The United States and Canadian Academy of Pathology, Inc.

VOL. 13, NO. 10, P. 1115, 2000 Printed in the U.S.A.

Date of acceptance: April 20, 2000. topathologically, PML is characterized by demyelination of white matter, abnormal oligodendroglial nuclei, and atypical astrocytes (Alzheimer type I astrocytes) (1).

The mechanism of JCV-mediated demyelination is still not completely understood. Recent molecular biological studies have shed light on the interaction between JCV and the tumor suppressor p53 protein. p53 is an important regulator involved with the processes of cell proliferation and programmed cell death. It has been shown in vitro that JCV large T antigen, similar to SV40 large T antigen, can form a complex with wild-type p53 protein (3). In vitro studies have demonstrated that such an association between viral large $\mathrm{T}$ antigen and wild-type p53 protein abrogates the transcriptional function of the p53 protein $(3,4)$. p53 protein, stabilized by JCV, can be immunohistochemically detected in JCVinfected oligodendrocytes due to a prolonged halflife $(5,6)$. Further studies have provided evidence that such loss of p53 function is associated with the overexpression of proliferative cell nuclear antigen (PCNA) and DNA amplification in JCV-infected cells $(5,7)$. The significance of such an association is not clear, since it is well known that PML is a predominantly demyelinating process.

Recent studies examining other demyelinating diseases, such as multiple sclerosis and spinal cord injury, indicate that oligodendrocyte apoptosis contributes to the loss of oligodendrocytes and may be responsible for the demyelination of axons in the central nervous system $(8,9)$. Further evidence suggests that p53 may be directly involved in oligodendrocytic apoptosis, which is induced by certain cytokines $(10,11)$. Apoptosis is a complex cellular process involving multiple factors and steps biochemically. The balance of two cellular protein families, a pro-apoptotic protein Bax and an antiapoptotic protein Bcl-2, influences a cell's fate through a p53-dependent apoptotic pathway (12). Wild-type p53, but not mutant p53, directly upregulates the transcriptional expression of Bax and indirectly downregulates the expression of Bcl-2 (1315). Overexpression of Bax and downregulation of Bcl-2 represents an actively apoptotic process in 
the cells (12), whereas overexpression of Bcl-2 and downregulation of Bax is frequently detected in neoplastic cells (16). To determine whether human PML is an apoptotic process induced by JCV, we immunohistochemically studied the expression of p53, Bcl-2, and Bax in viral-infected glial cells in 14 cases from 13 PML patients.

\section{MATERIALS AND METHODS}

Fourteen formalin-fixed and paraffin-embedded PML specimens, derived from 13 patients (10 males and three females), including 10 biopsies and four autopsies were used in this study. One case had both biopsy and autopsy specimens available. The patients' mean age was 48 years (range, 29 to 79 years). Seven patients were known to be HIV positive, three patients had non-Hodgkin's lymphoma and had completed chemotherapy, one patient had Hodgkin's lymphoma and had completed chemotherapy, one patient had systemic lupus erythematosus with long-term immunosuppressive therapy, and one patient had renal cell carcinoma requiring regular hemodialysis (Table 1 ).

Tissue was routinely fixed in $10 \%$ buffered formalin with about 12 hours fixation for biopsy specimens and about 2 weeks fixation for autopsy specimens. Paraffin-embedded tissue sections were stained with either hematoxylin-eosin (biopsy specimens) or with modified Kluver Barrera (autopsy specimens). In nine cases, an ultrastructural evaluation was performed at the time of initial diagnosis.

Immunohistochemical analysis of p53, Bcl-2, and Bax expression was performed with a labeled streptavidin-biotin system by means of an automated immunostainer (Ventana Medical Systems, Tucson, AZ). After deparaffinization and dehydration in xylene and graded alcohols, the slide was immersed in distilled water, and the section was transferred to an acetate buffer solution for antigen retrieval at $\mathrm{pH} 7.0$ and microwaved for $15 \mathrm{~min}$. The sections were then incubated with a mouse monoclonal anti-p53 (DO7, 1:10, DAKO Corporation, Carpenteria, CA), a rabbit polyclonal anti-Bax (1:25, DAKO), and a mouse monoclonal anti-Bcl-2 (Ventana Medical Systems). Negative controls consisted of equivalent non-immune mouse immunoglobulin G. Sections were sequentially incubated with biotinylated anti-mouse immunoglobulin G, streptavidin-horseradish peroxidase, with a chromogenic substrate aminoethycarbazole, and hematoxylin counterstaining, with intervening buffer washes. Reddish brown nuclear staining was interpreted as being positive for p53; perinuclear cytoplasmic staining was interpreted as being positive for Bcl-2; and cytoplasmic staining was interpreted as being positive for Bax. The positive control for p53 staining was a resection specimen of human colon adenocarcinoma. Specimens used as negative controls for p53 included one case of nonnecrotizing granulomatous inflammation and one case of herpes simplex encephalitis. The positive control used for Bax was a normal human colon mucosa. Positive control for Bcl-2 was a tonsil with lymphoid hyperplasia.

\section{RESULTS}

\section{Histopathology of PML Lesions}

Gross examination of four autopsy brains revealed multiple tan-gray soft lesions situated in the cerebral hemispheric white matter. The cortex and deep gray matter were spared. Microscopically, at least one demyelinative focus was identified in each of the biopsy cases. Multiple foci of demyelination were seen in all four autopsy cases and some of the biopsy specimens. Typically, demyelinating lesions exhibited a relatively hypocellular center and was sometimes marked by the formation of microcysts. An abundance of oligodendrocytes with enlarged nuclei and Cowdry A inclusions were usually found

TABLE 1. Clinical Data of Patients with Progressive Multifocal Leukoencephalopthy

\begin{tabular}{rllll}
\hline Case No. & Age/Sex & \multicolumn{1}{c}{ Specimen } & \multicolumn{1}{c}{ Location } \\
\hline 1 & $52 / \mathrm{M}$ & Biopsy and autopsy & L frontal lobe, brain stem and spinal cord & CLL, s/p chemotherapy \\
2 & $64 / \mathrm{M}$ & Biopsy & L frontal lobe & lymphoma \\
3 & $46 / \mathrm{M}$ & Biopsy & L frontal lobe & HIV positive \\
4 & $32 / \mathrm{M}$ & Biopsy & L occipital lobe & HIV positive \\
5 & $79 / \mathrm{M}$ & Biopsy & R parietal lobe & RCC, essential thrombocytosis \\
6 & $71 / \mathrm{F}$ & Biopsy & R occipital lobe & renal transplantation, s/p hemodialysis \\
7 & $35 / \mathrm{M}$ & Biopsy & bil frontal lobes & HIV positive \\
8 & $35 / \mathrm{M}$ & Autopsy & frontal and occipital lobes, basal ganglion & HIV positive \\
9 & $71 / \mathrm{F}$ & Autopsy & R frontal lobe & CLL, s/p chemotherapy \\
10 & $68 / \mathrm{F}$ & Biopsy & L frontal lobe & HIV positive \\
11 & $44 / \mathrm{M}$ & Biopsy & cerebral peduncle & Hodgkin's disease \\
12 & $39 / \mathrm{M}$ & Autopsy & brain stem & HIV positive \\
& & & R frontal lobe & HIV positive \\
\hline
\end{tabular}

M, male; F, female; R, right; L, left; bil, bilateral; s/p, status post; SLE, systemic lupus erythematosus; CLL, chronic lymphocytic lymphoma; HIV, human immunodeficiency virus; RCC, renal cell carcinoma. 
at the peripheral zone of the lesions (Fig. 1A). Atypical astrocytes (Alzheimer I astrocytes) with enlarged and hyperchromatic nuclei were often intermixed. Prominent numbers of infiltrating macrophages were observed in foci of demyelination. Perivascular lymphocytic infiltrates were often present. The surrounding uninvolved white matter and adjacent gray matter were microscopically unremarkable. There was no significant morphologic difference between HIV positive cases and HIV negative cases.

\section{Expression of P53 Protein}

Strong nuclear p53 immunostaining was seen in infected oligodendrocytes in all cases. In wellformed demyelinating lesions, p53-positive oligodendrocytes were usually distributed at the peripheral zone of the lesions (Fig. 1B). Atypical astrocytes adjacent to the PML lesions were positive for p53 in eight cases. Macrophages within the demyelinating lesion were negative for p53. Oligodendrocytes and reactive astrocytes from two control cases, including herpes simplex encephalitis and non- necrotizing granulomatous inflammation, were negative for p53.

\section{Expression of Bax}

Bax immunostaining was not observed in uninfected oligodendrocytes and astrocytes in uninvolved white matter. In contrast, strong cytoplasmic immunostaining of Bax was observed in the majority of the enlarged infected oligodendrocytes in all the demyelinating lesions of the PML (Fig. 1C). The number of Bax-positive oligodendroglial cells correlated with the number of p53-positive cells. Bax immunostaining was also observed in macrophages infiltrating in foci of the demyelination (Fig. 1C).

\section{Expression of $\mathrm{Bcl}-2$}

No immunostaining with Bcl-2 was observed in either infected or uninfected oligodendrocytes and astrocytes (Fig. 1D). However, Bcl-2 immunostaining was observed in the infiltrating lymphocytes, both infiltrating within the lesion and surrounding

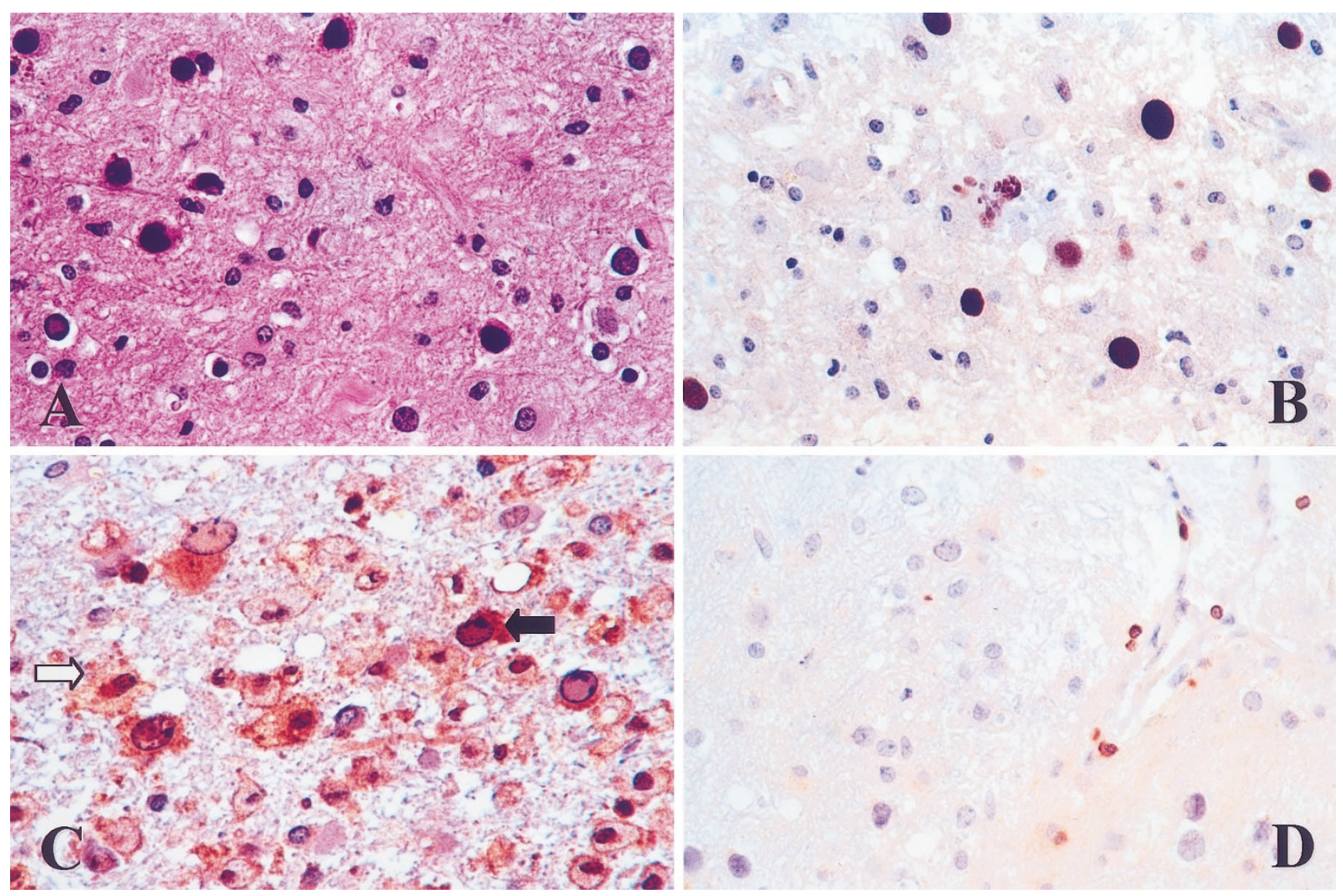

FIGURE 1. Expression of p53, Bax, and Bcl-2 in PML. A PML lesion in the white matter shows enlarged oligodendroglial nuclei with intranuclear inclusions at the peripheral zone of the lesion in hematoxylin and eosin stained brain tissue (A) at $200 \times$ magnification. Immunohistochemical staining of the PML lesion with antibodies to p53 (B), Bax (C), and Bcl-2 (D) at 200× magnification. Strong expression of p53 was detected in JCVinfected oligodendrocytes in B. C shows the expression of Bax in infected oligodendrocyte (solid black arrow), reactive macrophage (white arrow), and some atypical astrocytes. Expression of Bcl-2 was only detected in lymphocytes surrounding the perivascular space shown in $\mathbf{D}$. 
the perivascular space (Fig. 1D). Morphologically, these Bcl-2-positive lymphocytes were small with a smooth nuclear contour. Macrophages within the demyelinating lesions did not stain for Bcl-2.

\section{DISCUSSION}

PML is a demyelinating disease resulted from infection of oligodendrocytes with predominantly JCV, although other viruses (such as HHV6) may also play a role in the pathogenesis of PML (17). Histopathologically, PML is characterized by multiple areas of demyelination, enlarged oligodendroglial nuclei with basophilic viral inclusions, and Alzheimer type I astrocytes (1). Oligodendrocytes are the main myelin producing cells in the central nervous system (CNS). The mechanism of JCVmediated demyelination in PML is yet unknown. It has long been speculated that JCV targets oligodendroglial cells and the gradual lytic destruction of oligodendrocytes contributes to the demyelination that characterizes the pathology.

Recent studies in other CNS demyelinating diseases have indicated that demyelination is partly the result of oligodendroglial cell apoptosis derived from a variety of causes $(8,9,18)$. In vitro studies have demonstrated that upon exposure to growth stimulation, mature oligodendrocytes overexpressed PCNA and $c$-fos genes, but failed to divide, and ultimately underwent cell death by apoptosis (19). P53 plays an important regulatory role in programmed cell death in the central nervous system (11). In particular, p53 has been directly implicated in the process of oligodendrocyte apoptosis (10). It is believed that the intracellular balance of two apoptosis-related proteins, Bcl-2 and Bax, regulates the cell proliferation and cell death (12). Evidence from animal models likewise demonstrates that the balance of Bcl-2 and Bax is also critical in determining cell death in the CNS (20-22). Bcl-2 is an anti-apoptosis protein whose overexpression contributes to the uncontrollable proliferation of gliomas and other neoplasms $(21,23)$. In contrast, Bax, an antagonist of Bcl-2, is an apoptosis promoter and its overexpression often results in cellular apoptosis $(21,23,24)$. It has been shown that wildtype, but not mutant, p53 protein directly regulates the transcriptional expression of Bax (15), and indirectly regulates the expression of Bcl-2 $(13,14)$. In PML, it has been demonstrated in vitro that the large $\mathrm{T}$ antigen of JCV can form a protein-protein complex and result in an accumulation of p53 protein that can be detected by immunohistochemical staining (5-7). Whether p53 protein in viral-infected oligodendrocytes totally loses its wild-type function or PML results from oligodendrocyte apoptosis, through either p53-dependent or p53-independent pathways, has not been elucidated.
We studied the expression of p53, Bcl-2, and Bax in 13 patients with PML by immunohistochemistry. Overexpression of p53 was mainly found in viralinfected oligodendrocytes in all the cases and occasionally in atypical astrocytes. Interestingly, overexpression of Bax was also detected in the infected oligodendrocytes at the edge of demyelinating lesions, whereas no expression of Bcl-2 was detectable either in the infected oligodendrocytes or in atypical astrocytes. Such an overexpression of Bax and downexpression of Bcl-2 pattern may indicate that the viral-infected glial cells are in an active apoptotic state and may eventually undergo cell death through apoptosis. Our results are consistent with in vitro studies of Bax/Bcl-2 in other demyelinating diseases (25-28).

Interestingly, overexpression of both p53 and Bax were observed in the infected oligodendrocytes. This finding suggests that p53 protein, although complexed with the virus in PML, may still maintain its wild-type function and promote apoptosis through the upregulation of Bax. The functional status of the p53 in JCV-infected cells was further supported by the evidence that p53 is able transcriptionally to inhibit JC virus replication in vitro (4). It is possible that upon JCV infection, p53 overexpresses itself in response to the cellular stress and the high level of p53 expression, halting viral replication and promoting apoptosis through upregulating Bax and downregulating Bcl-2 in infected cells. The new balance of increasing Bax and decreasing Bcl-2 may lead oligodendrocyte apoptosis and demyelinating lesion formation. However, whether JCV-infected oligodendrocytes are truly apoptotic needs to be further confirmed by other apoptotic markers or analysis, such as an anti-caspase-3 immunostaining, TUNEL or ISEL methods.

The relationship between JCV and p53 may be more complex than our current understanding because p53 is also a crucial regulator of cell proliferation and malignant transformation (29). In vitro studies show that JCV large T antigen interacts with the same domain of p53 protein as SV40 T-antigen (4). SV40 can transform cultured cells in vitro by inactivating the function of the p53 (3). Whether JCV T-antigen functionally blocks the p53-mediated inhibitory effect on cell growth is still unknown. A recent study showed that the accumulation p53 protein in oligodendroglial cells was associated with the overexpression of a PCNA in some of the PML cases studied (5). This observation has led some to speculate that inactivation of p53 protein by JCV may allow cells to disorderly engage in DNA synthesis as a prelude to mitosis and proliferation $(5,7,30)$. However, the interpretation of the overexpression of a so-called "cell proliferation marker" should be made with caution. It has been shown that not all the cells expressing Ki-67 antigen were 
actively proliferating cells because many cell-cycle arrested cells, expressing both wild-type p53 and a cyclin-dependent kinase inhibitor p21, also showed Ki-67 positivity (31). In the presence of tumor suppressor gene $p 53$, overexpression of oncogenes and viral oncoprotein may induce cell death rather than cell proliferation (32-34). Our finding of Bax $+/ \mathrm{Bcl}-2$ - expression pattern in infected oligodendrocytes further suggests that these cells are most likely in an active apoptotic state rather than a proliferative state.

Overexpression of Bax and undetectable Bcl-2 was also observed in macrophages involved in the demyelinating process in PML. Although little is yet known regarding the functional significance of Bax and Bcl-2 expression in the microglial/macrophage lineage, marked changes in the pattern of their expression are likely to alter the life span of these reactive macrophages. Evidence of the role of Bax/ Bcl-2 families in the apoptotic pathway of macrophages/monocytes has been recently studied in human atherosclerotic plaques, giant cell granulomas and osteopetrosis (35-40). It is possible that these macrophages, after engulfing the degraded myelins, undergo apoptosis, and apoptotic macrophages may further enhance the development of demyelinating lesions by releasing cytokines. Recently, Krajewski et al. (21) reported that macrophages and microglial cells were more vulnerable to apoptosis in pediatric patients with HIV encephalitis than those without encephalitis. Because most PML patients are either HIV positive or had immunosuppressive conditions, it would be interesting to know whether immune status influences the life span of microglial cells in the CNS.

In summary, our findings of overexpression of Bax and downexpression of Bcl-2 pattern in viralinfected oligodendroglial cells suggest that oligodendrocyte may be undergoing apoptosis, which may contribute to the amount of demyelination in PML. The overexpression of both p53 and Bax in the infected oligodendroglial cells also suggests that p53 detected by immunohistochemistry may still maintain its wild-type function. Further studies with apoptosis labeling markers in PML lesions and studies of the functional status of p53 in PML will help us to understand the molecular mechanism of human PML.

\section{REFERENCES}

1. Astrom KE, Mancall E, Richardson E. Progressive multifocal leukoencephalopathy: a hitherto unrecognized complication of chronic lymphocytic leukemia and lymphoma. Brain 1958;81:93-111.

2. Berger JR, and Concha M. Progressive multifocal leukoencephalopathy: the evolution of a disease once considered rare. J Neurovirol 1995;1:5-18.

3. Frisque R, and White FI. The molecular biology of JCV, causative agent of progressive multiple leukoencephalopathy. In: Molecular neurovirology, Roos R, eds, Totowa: Human Press, 1992:25-158.

4. Staib C, Pesh J, Gerwig R, Gerber J-K, Brehm U, Stangl A, Grummt F p53 inhibits JC virus DNA replication in vivo and interacts with JC virus large T antigen. Virology 1996;219: 237-46.

5. Ariza A, Mate JL, Fernandez-Vasalo A, Gomez-Plaza C, Perez-Piteira J, Pujol M, Navas-Palacios JJ. p53 and proliferating cell nuclear antigen expression in JC virus-infected cells of progressive multifocal leukoencephalopathy. Hum Pathol 1994;25:1341-1345.

6. Lammie GA, Beckett A, Courtney R, Scaravilli F. An immunohistochemical study of p53 and proliferating cell nuclear antigen expression in progressive multifocal leukoencephalopathy. Acta Neuropathol 1994;88:465-471.

7. Ariza A, von Uexkull-Guldeband C, Mate JL, Isamat M, Aracil C, Cruz-Sanchez FF, Navas-Palacios JJ. Accumulation of wild-type p53 protein in progressive multifocal leukoencephalopathy: a flow of cytometry and DNA sequencing study. J Neuropathol Exp Neurol 1996;55:144-149.

8. Akassoglou K, Bauer J, Kassiotis G, Pasparakis M, Lassmann H, Kollias G, Probert L. Oligodendrocyte apoptosis and primary demyelination induced by local TNF/p55TNF receptor signaling in the central nervous system of transgenic mice: models for multiple sclerosis with primary oligodendrogliopathy. Am J Pathol 1998;153:801-813.

9. Shuman SL, Bresnahan JC, Beattie MS. Apoptosis of microglia and oligodendrocytes after spinal cord contusion in rats. J Neurosci Res 1997;50:798-808.

10. Eizenberg O, Faber-Elman A, Gottlieb E, Oren M, Rotter V, Schwartz M. Direct involvement of p53 in programmed cell death of oligodendrocytes. EMBO 1995;14:1136-1144.

11. Eizenberg O, Faber-Elman A, Gottlieb E, Oren M, Rotter V, Schwartz M. p53 plays a regulatory role in differentiation and apoptosis of central nervous system-associated cells. Mol Cell Biol 1996;16:5178-5185.

12. Barinaga M. Cell suicide: by ICE, not fire. Science 1994;263: $754-756$

13. Miyashita T, Harigai M, Hanada M, Reed JC. Identification of a p53-dependent negative response element in the bcl-2 gene. Cancer Res 1994;54:3131-3135.

14. Miyashita T, Krajewski S, Krajewska M, Wang HG, Lin HK, Liebermann DA, Hoffman B, Reed JC. Tumor suppressor p53 is a regulator of bcl-2 and bax gene expression in vitro and in vivo. Oncogene 1994;9:1799-1805.

15. Miyashita T, and Reed JC. Tumor suppressor p53 is a direct transcriptional activator of the human bax gene. Cell 1995; 80:293-299.

16. Krajewski S, Krajewska M, Ehrmann J, Sikorska M, Lach B, Chatten J, Reed JC. Immunohistochemical analysis of Bcl-2, Bcl-X, Mcl-1, and Bax in tumors of central and peripheral nervous system origin. Am J Pathol 1997;150:805-814.

17. Mock DJ, Powers JM, Goodman AD, Blumenthal SR, Ergin N, Baker JV, Mattson DH, Assouline JG, Bergey EJ, Chen B, Epstein LG, Blumberg BM. Association of human herpesvirus 6 with the demyelinative lesions of progressive multifocal leukoencephalopathy. J Neurovirol 1999;5:363-73.

18. Li YQ, Guo YP, Jay V, Stewart PA, Wong CS. Time course of radiation-induced apoptosis in the adult rat spinal cord. Radiother Oncol 1996;39:35-42.

19. Muir DA, and Compston DA. Growth factor stimulation triggers apoptotic cell death in mature oligodendrocytes. J Neurosci Res 1996;44:1-11.

20. Hara A, Hirose Y, Wang A, Yoshimi N, Tanaka T, Mori H. Localization of Bax and Bcl-2 proteins, regulators of programmed cell death, in the human central nervous system. Virch Arch 1996;429:249-253.

21. Krajewski S, James HJ, Ross J, Blumberg BM, Epstein LG, 
Gendelman HE, Gummuluru S, Dewhurst S, Sharer LR, Reed JC, Gelbard HA. Expression of pro- and anti-apoptosis gene products in brains from paediatric patients with HIV-1 encephalitis. Neuropathol Appl Neurobiol 1997;23:242-253.

22. Raff MC, Barres BA, Burne JF, Coles HS, Ishizaki Y, Jacobson MD. Programmed cell death and the control of cell survival: lessons from the nervous system. Science 1993;262:695-700.

23. Hara A, Hirose Y, Yoshimi N, Tanaka T, Mori H. Expression of Bax and bcl-2 proteins, regulators of programmed cell death, in human brain tumors. Neurol Res 1997;19:623-628.

24. Vekrellis K, McCarthy MJ, Watson A, Whitfield J, Rubin LL, Ham J. Bax promotes neuronal cell death and is downregulated during the development of the nervous system. Development 1997;124:1239-1249.

25. Bonetti B, Pohl J, Gao YL, Raine CS. Cell death during autoimmune demyelination: effector but not target cells are eliminated by apoptosis. J Immunol 1997;159:5733-5741.

26. Bonetti B, and Raine CS. Multiple sclerosis: oligodendrocytes display cell death-related molecules in situ but do not undergo apoptosis. Annu Neurol 1997;42:74-84.

27. Dowling P, Husar W, Menonna J, Donnenfeld H, Cook S, Sidhu M. Cell death and birth in multiple sclerosis brain. J Neurol Sci 1997;149:1-11.

28. Ferrer I, Pozas E, Lopez E, Ballabriga J. Bcl-2, Bax and Bcl-X expression following hypoxia-ischemia in the infant rat brain. Acta Neuropathol 1997;94:583-589.

29. Hartwell L. Defects in a cell cycle checkpoint may be responsible for the genomic instability of cancer cells. Cell 1992;71: 543-546.

30. Ariza A, Mate JL, Serrano S, Isamat M, Keysers U, Aracil C, Navas-Palacios JJ. DNA amplification in glial cells of progressive multifocal leukoencephalopathy: an image analysis study. J Neuropathol Exp Neurol 1996;55:729-733.

31. van Oijen MG, Medema RH, Slootweg PJ, Rijksen G. Positiv- ity of the proliferation marker Ki-67 in noncycling cells. Am J Clin Pathol 1998;110:24-31.

32. Hermeking H, and Eick D. Mediation of c-Myc-induced apoptosis by p53. Science 1994;265:2091-2093.

33. Lowe SW, Ruley HE, Jacks T, Housman DE. p53-dependent apoptosis modulates the cytotoxicity of anticancer agents. Cell 1993;74:957-967.

34. Jensen NA, Pedersen KM, Celis JE, West MJ. Failure of central nervous system myelination in $\mathrm{MBP} / \mathrm{c}$-myc transgenic mice: evidence for c-myc cytotoxicity. Oncogene 1998;16: 2123-2129.

35. Hamilton RFJ, Li L, Felder TB, Holian A. Bleomycin induces apoptosis in human alveolar macrophages. Am J Physiol 1995;269:L318-L325.

36. Hentunen TA, Jackson SH, Chung H, Reddy SV, Lorenzo J, Choi SJ, Roodman, GD. Characterization of immortalized osteoclast precursors developed from mice transgenic for both bcl-X(L) and simian virus 40 large $\mathrm{T}$ antigen. Endocrinology 1999;140:2954-2961.

37. Kockx MM, De Meyer GR, Muhring J, Jacob W, Bult H, Herman AG. Apoptosis and related proteins in different stages of human atherosclerotic plaques. Circulation 1998; 97:2307-2315.

38. Messmer UK, Reed UK, Brune B. Bcl-2 protects macrophages from nitric oxide-induced apoptosis. J Biol Chem 1996;271:20192-20197.

39. Pammer J, Weninger W, Hulla H, Mazal P, Horvat R. Expression of regulatory apoptotic proteins in peripheral giant cell granulomas and lesions containing osteoclast-like giant cells. J Oral Pathol Med 1998;27:267-271.

40. Selander KS, Monkkonen J, Karhukorpi EK, Harkonen P, Hannuniemi R, Vaananen HK. Characteristics of clodronateinduced apoptosis in osteoclasts and macrophages. Molec Pharmacol 1996;50:1127-1138. 